\title{
Ouvidoria interna como processo de interação nas organizações contemporâneas
}

Internal listening as a process of interaction
in contemporary organizations

La defensoría interna como un proceso de interacción en las organizaciones contemporáneas

Marlene Regina Marchiori

- Pós-doutora em Comunicação Organizacional pela Purdue University (EUA)

- Doutora em Ciências da Comunicação pela Escola de Comunicações e Artes da Universidade de São Paulo (ECA-USP), com estudos na Notthingham Trent University (Reino Unido)

- Graduada em Administração e em Relações Públicas pela Universidade Estadual de Londrina (UEL)

- Professora associada de graduação e de pós-graduação da UEL.

- Publicou: Cultura e comunicação organizacional; Faces da cultura e da comunicação organizacional (2 vol.); e Comunicação e organização: reflexões, processos e práticas

- marlenemarchiori@gmail.com 
Resumo

Este artigo aborda a ouvidoria interna como um espaço de diálogo nas organizações da contemporaneidade capaz de proporcionar permanentemente a participação e o intercâmbio das pessoas nos ambientes organizacionais. Nesse contexto, torna-se imprescindível a atitude e a disposição tanto das pessoas quanto da organização em praticar a interação, contextualizando as questões objetivas e subjetivas. Entende-se a ouvidoria como um dos processos organizacionais que possibilita a humanização nas organizações. Como conclusão, argumenta-se que a prática da ouvidoria interna nas organizações desponta como uma possibilidade de construir o saber organizacional, considerando o ser humano matéria-prima dessa edificação.

PALAVRAS-CHAVE: OUVIDORIA • OUVIDORIA INTERNA • HUMANIZAÇÃO • PESSOAS • COMUNICAÇÃO

\section{Abstract}

This article considers listener's office service as a space for dialogue in contemporary organizations, capable of providing permanent participation and exchange of people in organizational environments. In this context, the attitude and the willingness of both the people and the organization to practice interaction, contextualizing the objective and subjective questions, is essential. This article sees listener services as an organizational process that enables humanization of organizations. In conclusion, it is argued that the practice of internal listening services in organizations arises as a possibility of building organizational knowledge, considering the human raw materials of the building.

KEYWORDS: LISTENER • INTERNAL LISTENER • HUMANIZATION • PEOPLE • COMMUNICATION

Resumen

Este artículo considera la defensoría interna como un espacio de diálogo en las organizaciones contemporáneas, capaz de proporcionar permanentemente la participación y el intercambio de personas en los ambientes organizacionales. En este contexto se vuelven esenciales la actitud y la disposición, tanto de las personas como de la organización, para practicar la interacción, contextualizando las cuestiones objetivas y subjetivas. Se considera la defensoría como uno de los procesos que permiten la humanización de las organizaciones. En conclusión, se argumenta que la práctica de la defensoría en las organizaciones surge como una posibilidad de construir el conocimiento organizacional, considerando al ser humano como la materia prima de esa construcción.

PALABRAS CLAVE: DEFENSORÍA • DEFENSOR INTERNO • HUMANIZACIÓN • PERSONAS • COMUNICACIÓN 
Comunicação é uma das atividades predominantes em qualquer organização (HARRIS;NELSON, 2008), sendo um processo de relacionamento (CONDIT, 2006). Ouvidoria é uma ferramenta de consolidação da democracia (SILVEIRA; OLIVEIRA; PESSOA, 2008). A ouvidoria representa um tema de estudo comunicacional profícuo para os pesquisadores dessa área, com base em sua abordagem como "lugar de comunicação" (IASBECK, 2009). Ouvidoria deve ser entendida como uma possibilidade de interlocução entre a organização e seus públicos. Sales (2006, p. 155) assim define ouvidoria:

Serviço ao qual pode recorrer o cidadão, a fim de encaminhar sugestões, reclamações e denúncias, no sentido de preservar os princípios que devem nortear a conduta da administração pública, quais sejam: a legalidade, a legitimidade, a impessoalidade, a moralidade, a economia e a publicidade.

Ombudsman é um termo sueco que resulta da junção da palavra ombud - representante, procurador - com a palavra man - homem (VISMONA, 2000). Chussy Antunes et al. definem ombudsman como um agente externo à organização, sugerindo a ouvidoria como um serviço da administração, vinculado ao principal dirigente da organização para o acesso do cidadão. Segundo Luiz Carlos A. Iasbeck (2009, p. 1), nas áreas públicas se conservou o tradicional nome "ouvidoria", enquanto nas empresas privadas se utiliza o nome "ombudsman", sendo que o ouvidor ou o ombudsman "são os responsáveis nominais por fazer girar processos comunicativos entre empresa e clientes e entre clientes e empresas". No Brasil o código de defesa do consumidor, instituído pela Lei $\mathrm{n}^{\circ} 8078$, de 11 de setembro de 1990, trouxe inúmeras exigências, entre as quais a necessidade de instituir a ouvidoria, para acompanhamento da qualidade dos produtos e serviços, assim como para assegurar excelência no atendimento. Farias (2008) sugere que as mudanças também foram marcantes na relação entre organização e funcionário, em razão das negociações de acordos coletivos de trabalho, bem-estar do trabalhador, relações sindicais, entre outros aspectos. Essas mudanças possibilitaram às organizações refletir sobre sua postura interna e criar o canal de comunicação da ouvidoria interna, que tem como foco acolher denúncias, sugestões, elogios e reclamações essencialmente dos funcionários para a melhoria contínua de processos, práticas e relacionamentos em uma organização.

Este artigo tem dois objetivos. O primeiro: desenvolver e apresentar os elementos essenciais da ouvidoria interna, contribuindo para a reflexão sobre tornar imperativa a atitude e a disposição tanto das pessoas quanto da organização em praticar a interação. O segundo: relatar dados empíricos de uma pesquisa realizada nas " 150 melhores empresas para se trabalhar no Brasil", na qual a ouvidoria interna figura entre os canais de comunicação interna, o que sugere aos profissionais da área aprofundar os estudos nesse campo. Com esses objetivos em vista, o artigo apresenta uma discussão sobre as implicações da teoria e da prática nas organizações, sugerindo a ouvidoria interna como uma possibilidade de construção do saber, considerando-se o ser humano matéria-prima dessa edificação. 
O ombudsman não deve funcionar de forma opressiva na relação com os funcionários (SALES, 2006). A premissa mais significativa é que ele intermedeie conflitos reais e potenciais e contribua para sua solução, o que exige uma postura altamente ética no trato das questões de terceiros.

Conflitos são processos naturais, vistos como parte da vida organizacional (YEUNG, 1997), devendo ser tratados de forma construtiva, uma vez que as confrontações ajudam as organizações a se tornarem mais criativas (CHAMBERS, 1998). Trabalhar conflitos significa quebrar rotinas, mobilizar pessoas para entendimentos, respeitar diferenças. O aprimoramento das relações interpessoais e sociais nas organizações passa necessariamente por processos de administração do conflito (SALES, 2006).

\section{OUVIDORIA INTERNA}

Farias (2008) comenta que seria uma incoerência criar uma área de ouvidoria externa sem oferecer esse mesmo benefício internamente. Afinal, o que se busca quando se criam as ouvidorias internas? Resolver conflitos, tornar a organização aberta, ampliar relações, constituir espaços de fala, manifestar vozes que às vezes são reprimidas, inibir incivilidade no ambiente organizacional, aprender a respeitar pessoas, identificar contextos de manipulação de pessoas; vemos que esses procedimentos buscam o desenvolvimento de uma organização com mais qualidade. Essas respostas evidenciam a ouvidoria como uma possibilidade basilar para as organizações construírem a cidadania no nível microssocial, com base no diálogo que legitima a transparência, na busca do entendimento, do relacionamento e do conhecimento das pessoas. Pessoas constroem uma organização e são elas que fazem o que ela é, como entidade que se institucionaliza diante de inúmeros públicos.

Falar em ouvidoria interna sugere o entendimento da organização não somente como emissora, mas principalmente como receptora dos níveis intermediário e operacional, especialmente se considerarmos a ouvidoria como canal ascendente de comunicação, o qual, segundo Harris e Nelson (2008, p. 217), se desenvolve na figura do ombudsman: "representante que media diferenças". Esta mediação requer entender o "olhar de quem usa o serviço, vendo a empresa pelo lado de fora” (SILVEIRA; OLIVEIRA; PESSOA, 2008). Para Sales (2006, p. 159), mediação é um "procedimento consensual de solução de conflitos", graças ao qual as pessoas movidas pelo diálogo encontram uma alternativa ponderada, eficaz e satisfatória. O mediador é a pessoa que auxilia na construção do diálogo entre as partes (SALES, 2006).

Diante de tais circunstancias, é basilar entender que a prática da ouvidoria interna envolve aprender a ouvir e a responder, ou seja, há claramente um processo de troca, de respeito, entre a organização e as pessoas que falam, opinam, criticam, apresentam sugestões e contradições, sendo incontáveis 
as possibilidades de se manifestarem. Silveira, Oliveira e Pessoa (2008) afirmam que o feedback é indispensável para a existência saudável de um sistema de ouvidoria interna, opinião compartilhada por Cláudia S. de Jesus (2009), que afirma: o ouvidor deve criar uma relação de parceria e confiança, não deixando o usuário sem resposta. Ele deve apresentar como características a imparcialidade, a neutralidade, o senso de justiça, a rapidez na tomada de decisão e na mudança dos processos. Cardoso (2006) complementa: ser ouvidor implica reunir habilidades e capacitações múltiplas. Para Sales (2006, p. 156), o ombudsman deve dirigir atenção especial a alguns princípios e algumas regras de comportamento, destacando-se:

Transparência nos procedimentos administrativos e gerenciais; agilidade no atendimento às demandas; sigilo de informações e fatos; isenção no trato das demandas; uso de informações e documentos existentes na empresa; tratamento equânime em relação às partes.

É premente entender ouvidoria interna como uma possibilidade real de humanizar as relações internas a partir do momento em que a comunicação se faz. A comunicação acontece quando o processo de ouvir permite a reflexão da organização e se complementa com um novo comportamento, por mais simples que seja, mas que foi levado em consideração pela organização nos seus processos de ouvidoria interna. Assim, o diálogo se manifesta, se constrói naturalmente, à medida que a relação entre ouvir e agir se torna reconhecida e presente no ambiente organizacional.

Em todas as organizações, networks (redes) e canais são os métodos utilizados para troca de mensagens, informação, significado e conexões. Networks representam a comunicação interativa regularizada. A rede é uma estrutura social constituída por membros de um grupo e pelos relacionamentos ou laços entre eles (KEYTON, 2006). Para Nohria (1998, apud HARRIS; NELSON, 2008, p. 177), networks são "padrões da organização observáveis por meio da comunicação", são canais "organizacionalmente sancionados e são utilizados para estruturar o fluxo de informação, mensagens e possíveis significados" (HARRIS; NELSON, 2008, p. 177).

Dessa forma, passa a ser prioritária a existência de canais que fluam na organização e para isso é preciso observar se as redes propiciam o padrão de interação ou fluxos de mensagens entre os membros de um determinado grupo. Marchiori (2009) sugere a interação entre indivíduos como engrenagem fundamental para a sustentabilidade das redes de relacionamento, as quais devem priorizar a construção de significados. A ouvidoria interna pode ser considerada um canal ascendente de comunicação, mas somente será plena a partir do momento em que os fluxos interagirem e a interação sobrevier. À medida que a interação se desenvolve, as expectativas tornam-se interdependentes, pois as pessoas põem-se no lugar uma das outras, procuram perceber o mundo como 
as outras o percebem. Para Berlo (2003, p. 136), "os conceitos de fonte e receptor, como entidades distintas, perdem a significação e o conceito de processo aparece nítido". Pensar na ouvidoria interna como processo e não na relação entre ação e reação, na qual os atos dos participantes são inter-relacionados, é ter um pensamento organizacional contemporâneo.

Fica claro, portanto, que instituir a ouvidoria interna facilita os processos de reconhecimento da própria organização no ambiente interno, fundamentando-se sua identidade. Ou seja, o 'quem somos' (ALMEIDA, 2008) adquire sentido, uma vez que os funcionários vivenciam uma realidade da qual são parte integrante. Essa realidade se torna naturalmente refletida nos relacionamentos com os demais públicos da organização; assim há sintonia com o "como somos vistos” (ALMEIDA, 2008), sendo a imagem não só uma percepção, mas também um processo de interação com a organização. Portanto, organizações, que fazem valer seus esforços de relacionamento interno, conquistam espontaneamente os diferentes grupos.

Silveira, Oliveira e Pessoa (2008) entendem que a ouvidoria precisa de autonomia e apoio de toda a organização para funcionar como facilitadora do processo de comunicação. Não se trata, aqui, de disseminação da cultura da ouvidoria e sim de um trabalho que se estrutura naturalmente na organização, pelo qual as pessoas a reconhecem como um canal que respeita e pratica a interlocução, ou seja, o sujeito que fala ou escreve - o locutor - e alguém a quem a enunciação é dirigida - o interlocutor. Isso supõe necessariamente a existência de uma situação de comunicação entre duas ou mais pessoas. É no relacionamento entre um locutor e um interlocutor, em uma situação específica, que o enunciado ganha sentido. É preciso olhar para o ser humano de uma forma mais atenta, para vê-lo como o principal canal dos acontecimentos nas organizações (MARCHIORI, 2009, p. 294).

\section{OUVIDORIA, CIÊNCIA DO RELACIONAMENTO}

Sales (2006, p. 158) entende que "ouvidoria é, em essência, a ciência do relacionamento”. Exige-se, então, do ouvidor sensibilidade, intenso conhecimento sobre a organização, legislação e, principalmente, consciência e senso de justiça. Para Iasbeck (2009, p. 10), "não há relacionamento social civilizado que não esteja pautado nos princípios básicos de uma vida em sociedade." Relacionamentos não são instrumentalizações, são processos que se desenvolvem à medida que os sujeitos se manifestam na busca de sentido para suas ações. Relacionamento pode ser definido como o conjunto de expectativas que duas partes têm, uma em relação ao comportamento da outra, tendo como base seus padrões de interação (LEDINGHAM; BRUNING, 2000 , p. 178). Greenhalgh (2002, p. 12) nos orienta a observar o mundo dos negócios como "rede de relacionamentos, em vez de estruturas e proces- 
sos", entendendo que as pessoas, ao se sentirem incluídas e ao terem um sentido de comunidade, não querem mais vivenciar o antigo paradigma de interesse próprio, dominação e competição. Condit (2006, p. 4), por sua vez, afirma que "comunicação constitui relacionamentos que ao se fazerem reconstituem entidades que estão relacionadas”. Cada nível de relacionamento acaba sendo instituído por um conjunto de interações dinâmicas, não sendo a comunicação apenas um processo de transferência de informações ou disseminação de sinais. Portanto, é preciso identificar qual o sentido que as ouvidorias internas trazem para as organizações e o quanto elas constituem ou reconstituem os ambientes organizacionais ao ouvirem as manifestações dos seres humanos, tornando-as efetivamente dinâmicas, ampliando sua perspectiva como canais de interação e, portanto, de relacionamento.

É interessante constatar que as reflexões teóricas sugerem o entendimento da ouvidoria como uma possibilidade de construir conhecimento, à medida que, ao se ampliar o ouvir, se expande a capacidade de entendimento sobre a própria organização em razão da coleção de opiniões, de expressões, de interpretações do ser humano, ser que se manifesta pensando no desenvolvimento da organização. Quem convive, quem vivencia, tem oportunidade de contextualizar inúmeras experiências e ponderar sobre elas, sendo fundamental, como já discutido, o ouvir. Não basta às organizações somente ouvir, é essencial que se deem ao emissor as respostas. A construção do conhecimento se manifesta no saber. Gorz (2005, p. 32) assevera "o saber é antes de tudo, uma capacidade prática. [...] Uma cultura é tão mais rica quanto mais os saberes comuns de que ela é tecida lhe permitam integrar, transformar conhecimento novos em saberes".

Tais assertivas nos levam a construir uma organização de conhecimento, a qual "é condição e produto da implantação de uma comunicação de saberes, de forma que o fruto do trabalho seja consequência dos processos criativos e inovadores vivenciados pelos profissionais no cotidiano das organizações" (BULGACOV; MARCHIORI, 2010). As ouvidorias internas passam a ser um canal fundamental, a partir do momento em que colaboram na construção do saber organizacional, sendo primordial para isso relacionar-se.

Argumenta-se, portanto, que a prática da ouvidoria interna nas organizações desponta como uma possibilidade de construir o saber organizacional, considerando-se o ser humano matéria-prima dessa edificação.

Com base nesse referencial teórico exploram-se na sequência os resultados de uma pesquisa que inicialmente não teve a intenção de analisar especificamente a ouvidoria interna. Mas considera-se interessante a apresentação dos resultados, uma vez que os respondentes se referem à ouvidoria interna como um canal de comunicação presente nas 150 melhores empresas para se trabalhar no Brasil. 


\section{A OUVIDORIA INTERNA COMO UM CANAL DE COMUNICAÇÃO}

O estudo intitulado "A comunicação e suas práticas: uma análise nas 150 melhores empresas para se trabalhar no Brasil" foi um trabalho que visou identificar as práticas de comunicação brasileira e estreitar o diálogo entre a academia e o mercado. Neste relato de pesquisa, recortou-se, de uma investigação mais ampla, a questão relativa à identificação dos veículos de comunicação que as empresas utilizam na gestão da comunicação interna, uma vez que a ouvidoria interna é referenciada pelos respondentes da pesquisa como um canal de comunicação.

Trata-se de uma pesquisa descritiva, a qual, segundo Gil (2002), tem como objetivo a descrição das características de determinada população ou fenômeno. A pesquisa descritiva observa, registra, correlaciona e descreve fatos ou fenômenos de uma determinada realidade sem manipulá-los (TRIVIÑOS, 1990). Caracteriza-se pela seleção de amostras aleatórias de grandes ou pequenas populações sujeitas à pesquisa, visando obter conhecimentos empíricos atuais. Esse tipo de pesquisa leva a possibilidade de generalização sobre a realidade pesquisada, ao identificar a frequência com que o fenômeno acontece. A metodologia quantitativa é aplicada tanto na coleta quanto no tratamento das informações por meio de técnicas estatísticas. Com relação à coleta de dados, foi realizada uma pesquisa de campo que, como dizem Marconi e Lakatos (2004), "é utilizada com o objetivo de conseguir informações e/ou conhecimentos acerca de um problema, para o qual se procura uma resposta”.

Nosso estudo foi realizado no primeiro semestre de 2009, entre os meses de fevereiro e julho. Todas as unidades do universo que constam no Guia Exame das 150 melhores empresas para se trabalhar, do ano 2008, foram convidadas a participar da amostra (intenção censitária). Identificada a amostra, foi aplicado um questionário, classificado como estruturado.

A abordagem foi feita por e-mail. Em seguida, o instrumento foi postado na home page do Grupo de Estudos de Comunicação Organizacional e Relações Pùblicas $\left(\right.$ Gecorp $\left.^{1}\right)$, da Universidade Estadual de Londrina (UEL), com senha para acesso, requisitando-se dos sujeitos o termo de consentimento livre e esclarecido (TCLE). Obteve-se uma participação que pode ser considerada representativa: um total de 64 respondentes, o que significa $42,66 \%$ das pessoas consultadas. Apresentamos aqui o perfil dos respondentes e na sequência a tabulação e análise dos dados.

Quanto ao perfil dos respondentes no que se refere à idade, $79 \%$ deles tinham entre 20 e 40 anos; $47 \%$, entre 20 e 30 anos; e $32 \%$, entre 31 e 40 anos. Grande parte ocupava cargo de decisão: eram analistas, gerentes e coordenadores.

1 Ver: http//www.uel.br/grupo-estudo/gecorp/. 


\section{Gráfico 1 - Perfil dos respondentes}

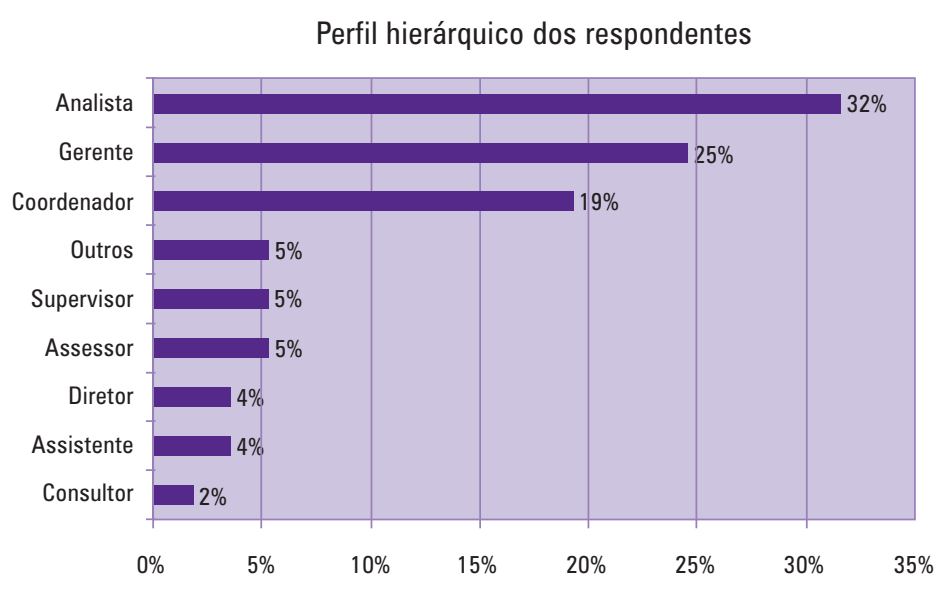

Fonte: Gecorp

Em relaçãoao gênero, $67 \%$ eram do sexo feminino; $28 \%$, do masculino; e 5\% não responderam. Já quanto ao tempo em que exerciam cargo de liderança, o destaque foi entre 1 e 5 anos.

\section{Gráfico 2 - Tempo em cargo de liderança}

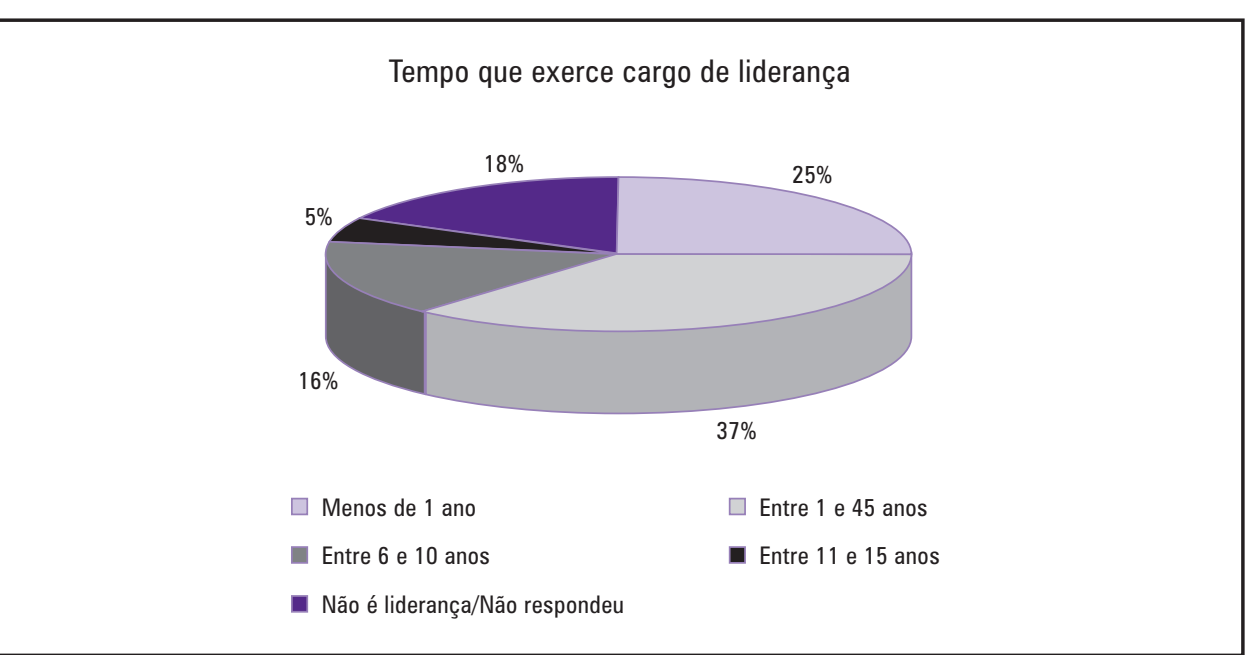

Fonte: Gecorp

Esse item evidenciou que grande parte dos respondentes estava no cargo há pouco tempo. Essa variável (tempo em que exerce cargo de liderança), junta- 
mente com a idade dos respondentes, reafirma o que outras pesquisas também revelam: caráter recente dos cargos de gestão da comunicação interna e a juventude da equipe que conduz essa área.

Gráfico 3 - Tempo na gestão da comunicação interna

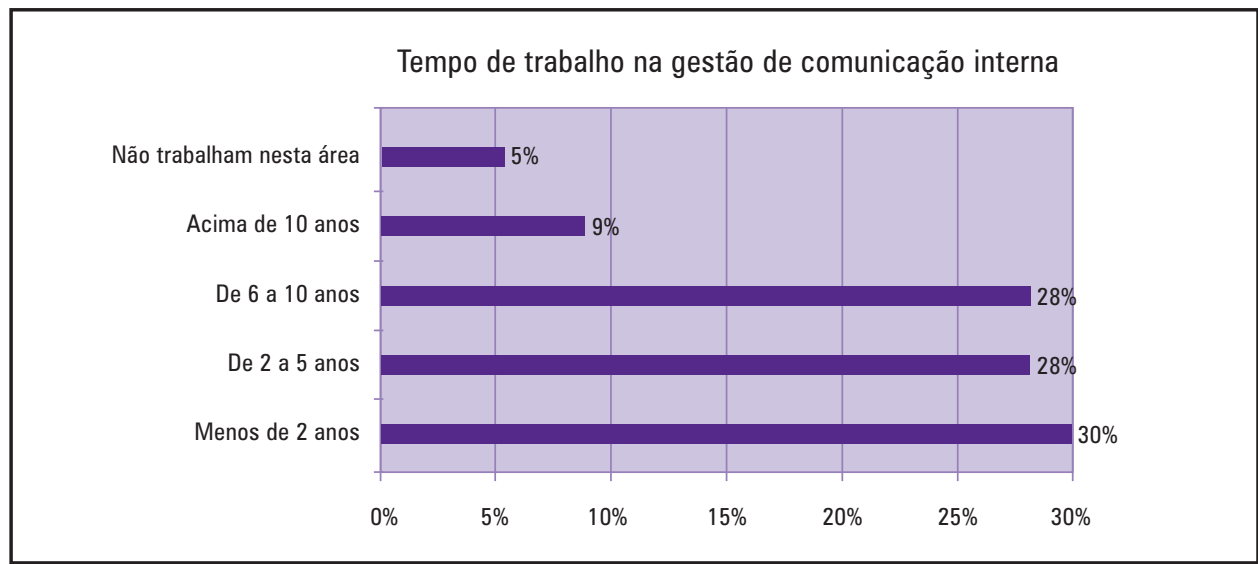

Fonte: Gecorp

Com relação ao tempo de trabalho, constatou-se que 57\% tinham menos de 5 anos de empresa; $26 \%$, entre 5 e 10 ano;, e 19\%, acima de 10 anos. Traçandose um paralelo do tempo em que os gestores estavam no cargo, nota-se que a maioria está há 10 anos, dado que coincide com o tempo de serviço na organização, que também é de 10 anos.

Quanto à formação educacional, nota-se que a maioria dos respondentes (68\%) possuía pós-graduação, fator que comprova a importância de especializações para adquirir cargos de liderança nas organizações. Totalizando 91\% com curso superior completo, a área profissional que mais se destacou foi a de administração (12\%), seguida de jornalismo (5\%). Empatados com 4\% apareceram ciências econômicas e relações públicas. Entre as demais profissões citadas $(2 \%)$ se relacionavam: comunicação social, jornalismo e publicidade, pedagogia, psicologia e publicidade e propaganda. Dessa forma, os cursos de comunicação social de modo geral totalizaram $14 \%$.

A partir da apresentação do perfil dos respondentes explorou-se a questão que identificou os veículos de comunicação, tendo sido facultado ao respondente assinalar quantas alternativas julgasse necessárias, enumerando o grau de importância com que os veículos eram utilizados na organização. 


\section{Tabela 1 - Identificação dos veículos de comunicação utilizados na gestão da comunicação interna}

\begin{tabular}{|c|c|c|c|c|c|c|}
\hline Veículo & $\begin{array}{c}5 \\
\text { estrelas } \\
\end{array}$ & $\begin{array}{c}4 \\
\text { estrelas }\end{array}$ & $\begin{array}{c}3 \\
\text { estrelas } \\
\end{array}$ & $\begin{array}{c}2 \\
\text { estrelas } \\
\end{array}$ & $\begin{array}{c}1 \\
\text { estrela }\end{array}$ & $\begin{array}{c}\text { Não } \\
\text { marcou }\end{array}$ \\
\hline E-mail & 42 & 8 & 5 & 1 & 0 & 1 \\
\hline $\begin{array}{l}\text { Reuniões entre gestores } \\
\text { e seus empregados }\end{array}$ & 39 & 7 & 4 & 0 & 0 & 7 \\
\hline $\begin{array}{l}\text { Encontros entre gerentes } \\
\text { e supervisores }\end{array}$ & 37 & 5 & 2 & 4 & 0 & 9 \\
\hline Treinamentos & 35 & 7 & 6 & 1 & 1 & 7 \\
\hline Campanhas internas & 34 & 14 & 7 & 2 & 0 & 1 \\
\hline Reuniões & 33 & 11 & 8 & 1 & 0 & 4 \\
\hline Intranet & 29 & 7 & 10 & 4 & 2 & 5 \\
\hline Eventos para empregados & 28 & 12 & 9 & 2 & 0 & 6 \\
\hline $\begin{array}{l}\text { Encontros que informam } \\
\text { os rumos da organização }\end{array}$ & 28 & 7 & 7 & 3 & 2 & 10 \\
\hline $\begin{array}{l}\text { Encontros que discutem } \\
\text { os rumos da organização }\end{array}$ & 26 & 7 & 9 & 3 & 2 & 10 \\
\hline Jornal mural & 25 & 12 & 4 & 5 & 1 & 10 \\
\hline $\begin{array}{l}\text { Recepção e acolhimento } \\
\text { do empregado }\end{array}$ & 24 & 5 & 9 & 3 & 2 & 14 \\
\hline $\begin{array}{l}\text { Programações em datas } \\
\text { comemorativas }\end{array}$ & 23 & 12 & 13 & 3 & 0 & 6 \\
\hline $\begin{array}{l}\text { Palestras e eventos } \\
\text { similares }\end{array}$ & 23 & 9 & 10 & 4 & 1 & 11 \\
\hline Jornal & 21 & 7 & 2 & 2 & 2 & 25 \\
\hline Café com o presidente & 21 & 6 & 5 & 1 & 2 & 22 \\
\hline Revista & 19 & 3 & 6 & 1 & 1 & 26 \\
\hline Newsletter & 15 & 11 & 11 & 2 & 3 & 15 \\
\hline Ouvidoria interna & 14 & 4 & 8 & 4 & 2 & 25 \\
\hline Convenções & 11 & 5 & 6 & 5 & 3 & 27 \\
\hline Visita dirigida & 11 & 4 & 7 & 3 & 1 & 31 \\
\hline Boletim & 9 & 5 & 11 & 4 & 2 & 26 \\
\hline Caixa de sugestões & 9 & 2 & 11 & 3 & 3 & 29 \\
\hline Vídeos & 8 & 5 & 11 & 3 & 3 & 27 \\
\hline Rádio & 8 & 0 & 1 & 1 & 4 & 43 \\
\hline TV interna & 2 & 2 & 8 & 1 & 3 & 41 \\
\hline Blog & 1 & 1 & 4 & 3 & 5 & 43 \\
\hline Outros* & & & & & & \\
\hline
\end{tabular}

* Programa de Erros e Tesouros, inovações e melhorias; Mural de comunicação; Manual de integração Jantar com o presidente, Programa de sugestões; Destaque do mês; Portas abertas; Kaizen cards; internet ; Informativo de banheiro, Programa tipo msn; Feedback individual; Explicitação dos valores; Dia da troca (momento de um colaborador conhecer outra área com a qual tem contato); Almoço com o presidente; site. Os encontros que discutem os rumos da organização fazem parte do Processo de Planejamento (Auditorias de posição, Planejamentos operacionais, etc.).

Fonte: Gecorp 
Nas organizações estudadas, o veículo de comunicação de maior importância apontado pelas empresas foi o "e-mail", utilizado por 98,24\% dos entrevistados, com 73,68\% de importância máxima. "Campanhas internas" aparecem com a mesma frequência de uso, porém foram consideradas o veículo mais importante em 59, 64\% das respostas.

Percebeu-se forte presença do contato humano na gestão da comunicação interna, que apareceu como importante com 5 estrelas: por exemplo, "Reuniões entre gestores e seus empregados" (68,42\%), seguida de "Encontros entre gestores e supervisores" (64,91\%) e "Treinamentos" (61,40\%). Outros, como "Campanhas internas", "Reuniões", "Intranet", "Eventos para os empregados" e "Encontros que informam os rumos da organização" são considerados prioridade por aproximadamente $50 \%$ dos entrevistados.

Também foi possível perceber que as organizações utilizam timidamente mídias como blog e rádio, sendo que 75,44\% deixaram em branco essas opções; o mesmo aconteceu com TV interna (71,92\%) e Vídeos (47,63\%).

Parece-nos que a tendência faz referência a uma comunicação pautada mais em relacionamento, em aproximação, que propicia troca, do que em necessariamente manutenção do nível informacional da organização. A valorização do contato humano nos processos de gestão da comunicação interna se faz fortemente presente, podendo ser interpretada como uma corrente. No que tange especificamente à ouvidoria interna não se identificaram aspectos específicos, mas pode-se inferir das respostas a valorização da ouvidoria em maior proporção do que em convenções, visita dirigida, boletim, caixa de sugestões, vídeos, rádio, TV interna e blogs. Esse retrato nos permite sugerir uma disposição nas organizações para processos que possibilitem a manifestação da voz, da fala das pessoas.

Os resultados obtidos nos levam a identificar o direcionamento das organizações para a construção, formação e sustentação de relacionamentos, muito mais do que o ato de gerenciar que impõe pensamentos e comportamentos.

\section{CONSIDERAÇÕES FINAIS}

O ser humano é a matéria-prima da ouvidoria interna nas organizações contemporâneas. Ficou claro que o ombudsman deve agir no sentido de ouvir e dar retorno, não sendo opressivo na relação com os funcionários. Passa a ser significativo intermediar e contribuir para a solução de conflitos, dando voz às pessoas, potencializando o saber de cada ser humano que se aproxima e que deseja falar. A ouvidoria interna amplia as possibilidades de negociação, de respeito, do exercício dos valores, da disposição da organização em reconhecer e reavaliar seus movimentos, seus processos e suas práticas, vivenciando dessa forma uma realidade com muito mais qualidade. 
Organizações que ratificam a ouvidoria interna promovem a cidadania no seu cotidiano, no âmbito microssocial, certamente estão muito mais preparadas para a extensão desse processo a outros públicos, tornando a organização mais facilmente institucionalizada na sociedade. Construir espaços de diálogo, de interação, é uma questão desafiadora no contexto contemporâneo, no qual a cada novo discurso a realidade se altera. É fundamental que os seres humanos estejam interligados, compreendam os processos e se sintam parte dessa construção.

É premente entender a ouvidoria interna como uma possibilidade real de humanizar as relações internas a partir do momento em que a comunicação seja uma verdade construída de diferentes saberes que, ao se relacionarem, ajudam a construir uma organização que vivencia a comunicação como um processo que mobiliza conhecimento.

\section{REFERÊNCIAS}

ALMEIDA, Ana Luísa de Castro. A construçao do sentido sobre 'quem somos' e 'como somos vistos'. In: MARCHIORI, Marle. Vol 1. 2. ed. Faces da cultura e da comunicação organizacional. São Caetano do Sul, SP: Difusão Editora, 2008. p. 31-50.

ANTUNES, Chussy K. Souza ; FREITAS, Nancy M. de Barros; RIBEIRO FILHO, J. FRANCISCO. Ouvidoria: inter-relação entre o controle social e controle interno. Disponível em: <http://www2.ouvidoria.pe.gov.br/> . Acesso em: 01 fev. 2010.

BERLO, David K. 0 processo da comunicação: introdução à teoria e à prática. São Paulo: Martins Fontes, 2003.

BULGACOV, Sergio; MARCHIORI, Marlene. 0 ser e a comunicação dos saberes. In: MARCHIORI, M. (Org.). Faces da cultura e da comunicação organizacional. Vol. 2. São Caetano do Sul, SP: Difusão Editora, 2010. p. 105-120.

CARDOSO, Antonio Semeraro R. Ouvidoria X mediação: reflexões sobre um conflito. Cliente SA, jul. 2006. Disponível em: <http://www.abonacional.org.br/>. Acesso em: 05 nov. 2009.

CHAMBERS, Harry E. The bad attitude survival guide. Reading, MA: Addison-Wesley Longman, 1998.

CONDIT, Celeste M. Communication as relationality. In: SHEPHERD, Gregory J.; ST. JOHN, Jeffrey; STRIPHAS, Theodore G. (Ed.). Communication as...: perspectives on theory. Thousand Oaks, CA: Sage, 2006. p. 3-12.

FARIAS, Lúcia. Ouvidoria interna ou externa: quando optar por uma ou por outra ? Disponível em: <http://www.administradores. com.br/noticias/ouvidoria_interna_ou_externa_quando_optar_por_uma_ou_outra/19013/>. Acesso em: 15 out. 2009.

GIL, Antonio Carlos. Como elaborar projetos de pesquisa. 4. ed. São Paulo: Atlas, 2002.

GORZ, Adré. 0 imaterial: conhecimento, valor e capital. São Paulo: Anablume, 2005.

GRENHALGH, Leonard. Relacionamentos estratégicos: a chave do sucesso nos negócios. São Paulo: Negócio Editora, 2002.

HARRIS, Thomas E.; NELSON, Mark D. Applied organizational communication: theory and practice in a global environment. 3rd ed. New York: Lawrence Erlbaum Associates, 2008.

IASBECK, L. C. Ouvidoria, lugar privilegiado de comunicação organizacional. Disponível em : <http://www.ipea.gov.br/ouvidoria/ doc/ouvidoria_lugar_de_comunicacao.pdf > , Acesso em: 05 out., 2009.

JESUS, Cláudia Sampaio de. A ouvidoria como canal de comunicação nas instituições de ensino superior (IES): o Projeto da FaculdadeRuy Barbosa. Disponível em: <http://www.frb.br/ciente/2006_2/ADM/ADM.JESUS.etal.F1\%20_Rev.\%2020.11.06_2_.pdf>. Acesso em: 05 nov. 2009.

KEYTON, Joann Communicating in groups: building relationships for group effectiveness. 3rd ed. New York: University Press, 2006.

LEDINGHAM, John A.; BRUNING, Stephen D. Public relations as relationship management: a relational approach to the study and practice of public relations. 2000.

MARCHIORI, Marlene. As interconexões entre cultura organizacional e comunicação. In: KUNSCH, Margarida M. Krohling (Org.). Comunicação organizacional. Vol 2. Linguagem, gestão, perspectivas. São Paulo: Saraiva, 2009. 
MARCONI, Marina de Andrade; LAKATOS, Eva M. Metodologia científica. 4. ed. São Paulo: Atlas, 2004.

SALES, Lília Maia de Morais. Ouvidoria e mediação: instrumentos de acesso à cidadania. Pensar, v. 11, p. 154-167, fev 2006.

SILVEIRA, Edagar Faria; OLIVEIRA, Nailton Alves de; PESSOA, Eliana. A ouvidoria como facilitadora do processo de comunicação organizacional. Disponível em: <http://www.administradores.com.br/artigos/a_ouvidoria_como_facilitadora_do_processo_de_comunicacao_organizacional/24849/> . Acesso em: 18 out. 2009.

TRIVIÑOS, Augusto N. Silva. Introdução à pesquisa em ciências sociais. São Paulo: Atlas, 1987.

VISMONA, Edson Luiz. A ouvidoria no Brasil e seus princípios. In: ABO. A ouvidoria no Brasil. São Paulo: Imprensa Oficial do Estado, 2000.

YEUNG, Lorrita N. T. Confrontation or resolution management: discourse strategies for dealing with conflict in participative decision making. Journal od Applied Management Studies, v. 6, n. 1 p. 60-73, 1997.

Recebido em: 01.12.2009 / Aceito em: 01.02.2010 